\title{
Regional climate variations in south America over the late Holocene
}

\section{Malargüe, Argentina, 4-7 October 2006}

\author{
M. Grosjean ${ }^{1}$ and R. Villalba ${ }^{2}$ \\ 1NCCR Climate, University of Bern, Switzerland; grosjean@giub.unibe.ch \\ ${ }^{2}$ ANIGLA-CRICYT, Mendoza, Argentina; ricardo@lab.cricyt.edu.ar
}

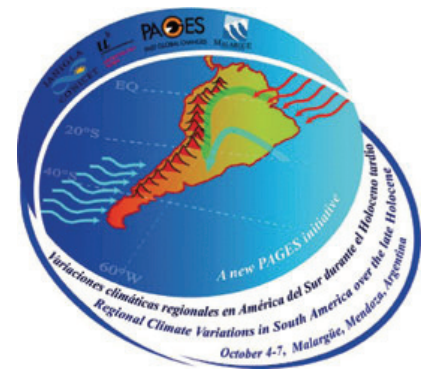

LOTRED-SA (Long-term climate reconstruction and diagnosis in South America) is a new PAGES research initiative (PAGES News, Vol. 13 No. 2). This collaborative effort aims at collating existing data sets to produce a comprehensive high-resolution multi-proxy reconstruction of regional climate in South America over the last few millennia.

Hosted by the city of Malargüe, Argentina and organized by PAGES, the Instituto Argentino de Nivologia, Glaciologia y Ciencias Ambientales (IANIGLA) and the University of Bern, Switzerland, LOTRED-SA held its first science conference from 4-7 October 2006. 133 scientists from 17 countries (mainly from Argentina, Chile, Brazil, Switzerland and USA, among them many members of the PAGES Scientific Steering (ommittee) joined for review keynotes, and oral and poster presentations of new paleoclimate data sets and research activities.

The objective of the conference was to gather experts from different fields in climate dynamics, diagnosis and paleoclimatology (data and models) to review the existing knowledge and data sets, to discuss the interpretation of natural and documentary proxy data, to search for calibration and quantification techniques of proxy data sets in South America, and to discuss the implementation plan for the PAGES Research Initiative LOTREDSA. The long-term goal and vision of this collaborative effort is to work towards a comprehensive view of regional climate variability and environmental change back in time (ca. 1000 years), and to produce a gridded data set of climate variables from high-resolution (sub-decadal) multi-proxy time series.

The conference sessions were organized along the lines of the research plans of LOTRED-SA, PAGES/CLIVAR and PAGES Focus 5 "Past Ecosystem Processes and Human-Environment Interactions". Accordingly, the presentations were grouped into sessions dealing with present climate variability; past climate variability inferred from historical documents; tree rings; lake and marine records; high-resolution pollen records; ice

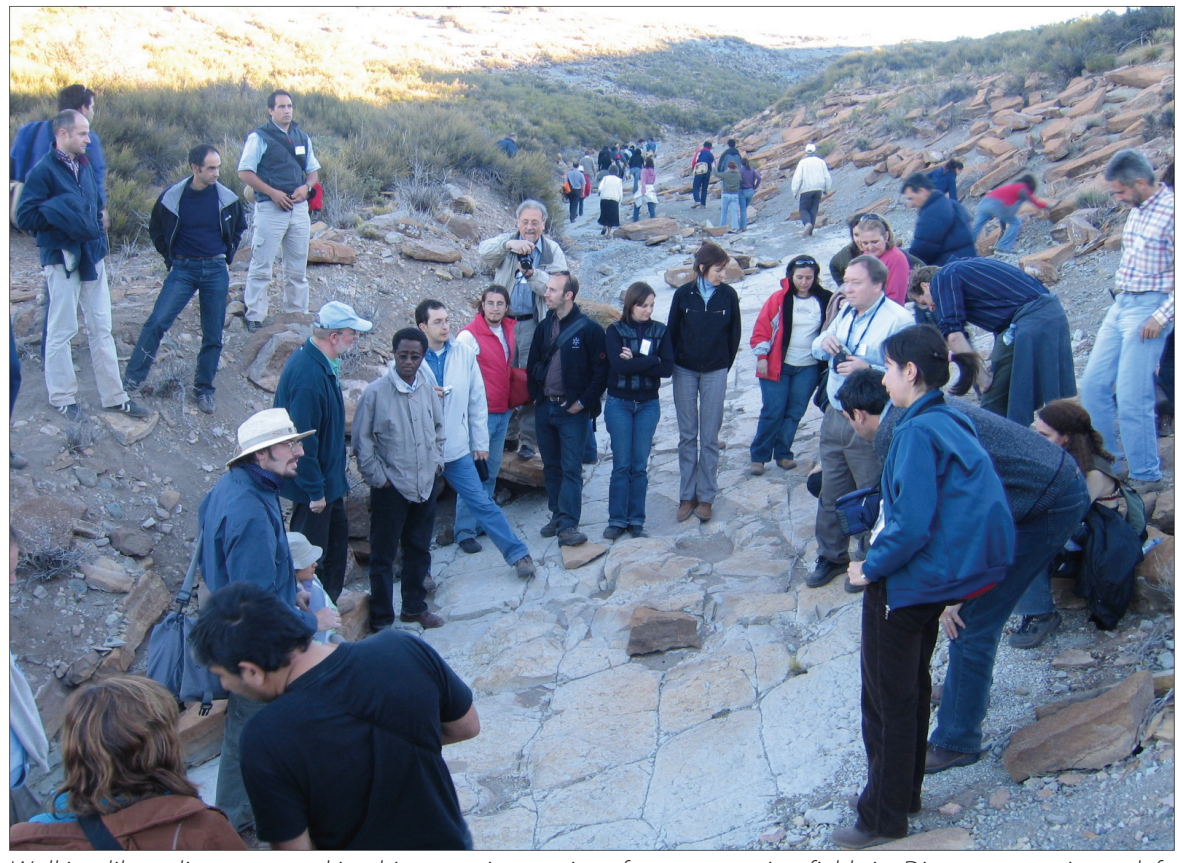

Walking like a dinosaur - making big steps: impressions from an evening fieldtrip. Dinosaur sceptics up left: glaciologists Patrick Ginot and Christoph Kull, biologist Antonio Maldonado.

thems; and human-climate interactions in South America during the past three millennia.

The most noteworthy outcomes were: (i) In contrast to the general perception, there is actually a considerable number of high-quality data sets available, mainly from tree rings and documentary data sources. (ii) Besides sampling resolution and dating, the main challenges for most natural proxy archives (ice cores, lake and marine sediments) are the calibration with meteorological time series and the quantification of paleoclimate information. (iii) Increasing sampling resolution, discriminating climate from land-use effects in proxies, and quantifying the paleoclimate signal remain the main challenges for paleovegetation archives. (iv) The paleoclimate research community in South America is well connected, enthusiastic and ready to take collaborative leadership in the LOTREDSA venture. It is very much hoped that other research communities in different regions of the world will follow the South American example.

The plenary of the conference agreed on the following implementation plan:

1) Early 2007: Meta-data database of existing proxy data sets established. The conference proceedings including review papers and original research articles will be the first intermediate product (special issue in Palaeo3).

2) 2007: Evaluation and selection of data sets, geographic areas, time window and resolution for the multi-proxy reconstructions.

3) 2007-08: Construction of a shared and protected database with proxy data sets, and evaluation/discussion with the authors. The results will be presented in a special issue of the PAGES newsletter (ca. 2008).

4) 2008: Actual multiproxy reconstruction and joint publication by all the contributors.

5)Ca. 2009: Next science meeting with PAGES, possibly in the context of the 3rd PAGES Open Science Meeting.

Guidelines for collaboration and contributions to LOTRED-SA are available at www.pages-igbp.org/science/initiatives/ lotred-sa/ or by contacting one of the authors or the PAGES office. 